\title{
JURISPRUDENCIA AMBIENTAL EN LA RIOJA (PRIMER SEMESTRE 2017)
}

\author{
María del CARMen Bolaño Piñeiro \\ Doctora en Derecho. Profesora de Derecho Administrativo \\ Universidad del País Vasco / Euskal Herriko Unibertsitatea
}

Sumario. 1. Panorámica general. 2. Nulidad de la señalización óptico-luminosa de los vehículos de los agentes forestales establecida en la Orden 38/2015. 3. Vertidos.

\section{PANORÁMICA GENERAL}

Como viene siendo habitual, son escasas las sentencias dictadas en materia medioambiental por el Tribunal Superior de Justicia de La Rioja en el semestre objeto de recopilación. En esta crónica se va a dar cuenta de dos, una por la que se declara la nulidad de un precepto de la Orden 38/2015, y otra por la que se declara la pertinencia del cambio de los términos de la autorización de vertidos al río Iregua de una piscifactoría.

\section{NULIDAD DE LA SEÑALIZACIÓN ÓPTICO-LUMINOSA DE LOS VEHÍCULOS DE LOS AGENTES FORESTALES ESTABLECIDA EN LA ORDEN 38/2015}

En la Sentencia del Tribunal Superior de Justicia de La Rioja 300/2016, de 24 de octubre, se analiza como objeto de recurso un precepto de la Orden 38/2015, de 29 de septiembre, de la Consejería de Agricultura, Ganadería y Medio Ambiente, por la que se desarrollan y modifican los Anexos II y III del Decreto 23/2009 de 15 de mayo, por el que se aprueba el Reglamento de Agentes Forestales de la Comunidad Autónoma de La Rioja. En concreto, la controversia venía dada porque el apartado cinco in fine del anexo III de la norma establecía que la señalización de los vehículos de los agentes forestales debería realizarse por medio de una señal óptico-luminosa de color azul.

La Abogacía del Estado recurre el precepto citado al entender que es contraria a la normativa estatal, señalando específicamente los artículos 149.1.21 de la 
CE, $\underline{4}$ y $\underline{61.1}$ del Real Decreto Legislativo 6/2015, de 30 de octubre, por el que se aprueba el texto refundido de la Ley sobre Tráfico, Circulación de Vehículos a Motor y Seguridad Vial, y el anexo XI, párrafo tres, del apartado "V-1 Vehículo propietario"” del Real Decreto 2822/1998, de 23 de diciembre, por el que se aprueba el Reglamento General de Vehículos. Específicamente, en el anexo XI del Real Decreto 2822/1998 se establece que los vehículos de extinción de incendios deberán llevar la señalización luminosa de color amarillo, razón por la cual la normativa autonómica sería contraria a la norma estatal básica. La Comunidad Autónoma de La Rioja, por su parte, señalaba que la disposición final segunda del Real Decreto Legislativo 6/2015, de 30 de octubre, por el que se aprueba el texto refundido de la Ley sobre Tráfico, Circulación de Vehículos a Motor y Seguridad Vial, habilita al Gobierno central para que desarrolle la norma mencionada y establezca que la señalización de todos los vehículos prioritarios sea azul.

El Tribunal da la razón al Estado señalando, principalmente, que, aunque es cierto que la previsión del Real Decreto Legislativo 6/2015 contempla que el Gobierno central está habilitado para extender el color azul a todos los vehículos prioritarios, este aún no ha procedido a su desarrollo, por lo que por el momento seguiría siendo de aplicación la normativa que señala que el color azul será de uso exclusivo por los vehículos de policía. De esta forma, el Tribunal declara la nulidad de pleno derecho del apartado cinco in fine del anexo III de la Orden 38/2015.

\section{VERTIDOS}

En la Sentencia del Tribunal Superior de Justicia de La Rioja 46/2017, de 9 de febrero, se resuelve el recurso contra la Resolución de la Confederación Hidrográfica del Ebro de 11 de marzo de 2015, por la que se deja sin efecto la anterior autorización de vertido a la piscifactoría recurrente y se establecen los nuevos términos de esta, que son más exigentes que los anteriores.

La Confederación Hidrográfica del Ebro elaboró dos informes entre 2014 y 2015. El primero indicó que se habían encontrado hongos y fitoplancton en el vertido de la piscifactoría; el segundo propuso revisar, dada la presencia de dichos organismos, la autorización del vertido de la piscifactoría. Como 
consecuencia, la Confederación Hidrográfica del Ebro estableció nuevos términos en la autorización que tenían en cuenta las nuevas circunstancias, ya que, según destacaban los informes, la calidad del agua estaba disminuyendo, lo que suponía un riesgo potencial para las poblaciones abastecidas con ella en concreto, Logroño y sus alrededores-. La piscifactoría recurrente argumenta que cumple en todo momento los estándares establecidos en las normas y que el cumplimiento de los nuevos estándares le supondría tener que realizar una inversión que devendría fatal para su negocio.

El Tribunal da la razón a la Confederación Hidrográfica del Ebro basándose en los informes de esta. En ellos se señala que deben extremarse las precauciones en la calidad del agua teniendo en cuenta los usos para abastecimiento de las aguas del río más allá de los vertidos de la piscifactoría y el deterioro de la calidad del agua del río Iregua - extremo que no se rebate por la demandante-. Estos hechos habilitarían a la Confederación a cambiar los criterios de la autorización, ya que, según apunta el Tribunal, las zonas de captación de agua para el consumo humano deben ser objeto de protección especial conforme a la Directiva Marco del Agua. Finalmente, se añade que es también un hecho a tener en cuenta que la piscifactoría se encuentre dentro del espacio protegido de la red Natura Peñas de Iregua, Leza y Jubera. Por estas razones, el Tribunal no anula la resolución por la que se establecen los nuevos criterios. 